Diverse Population, Diverse Collection? Page 1 of 32

\title{
Diverse Population, Diverse Collection? Youth Collections in the United States
}

\begin{abstract}
Authors
Virginia Kay Williams, Acquisitions Librarian, Wichita State University, 1845 Fairmount Dr., Wichita, Kansas 67260-0068, ginger.williams@wichita.edu

Nancy Deyoe, Assistant Dean for Technical Services, Wichita State University, 1845 Fairmount Dr., Wichita, Kansas 67260-0068, nancy.deyoe@wichita.edu
\end{abstract}

Acknowledgements: The authors gratefully acknowledge the support provided by the Amigos Fellowship and Opportunity Award in collecting and analyzing data for this study.

Abstract. Do school, public, and academic library collections in the United States provide the children, young adults, and future teachers we serve with books that reflect diverse families and life experiences? Using checklists and OCLC holdings, the authors assessed the extent to which libraries collect youth literature that includes characters from racial and ethnic minorities, characters with disabilities, and characters who identify as LGBTQ. They also assigned public libraries to Conspectus levels and compared youth-diversity holdings by collection expenditures. They found that more than one-third of public libraries spending over \$100,000 annually on materials did not achieve the minimal level for representations of diversity in their youth collections, indicating a need for local assessments and additional efforts to provide diverse youth collections.

Keywords: children's literature, young adult literature, diversity, Hispanic, Latino, African American, Asian Pacific Islander, disability, LGBTQ

This is an electronic version of an article published Technical Services Quarterly, Volume 31, Issue 2, (2014), pp. 97-121. DOI: 10.1080/07317131.2014.875373. Technical Services Quarterly is available online at http://www.tandfonline.com/. 
Casual conversations were the impetus for this study. One of the authors talked about working with a new faculty member who requested that the library acquire more culturally authentic Hispanic and Asian American picture books that she could use with her teacher-education students. The other author brought a copy of the Rainbow List home from a conference and mentioned a friend who had lamented that the “middle class, white, straight” bias in library collections meant he seldom found a character with whom he could identify. Other conversations touched on changing demographics in Kansas, the likelihood that a Coretta Scott King Honor Book about a blacksmith would find readers, fond memories of reading Beverley Butler's Light A Single Candle about a teenager who lost her sight, the relatively new American Indian Youth Literature Award, the value of academic freedom for academic librarians who wanted to acquire controversial children's books, and the challenge of identifying culturally authentic picture books about religious holidays. These casual conversations led to the question: How well do library youth collections reflect the diverse families and life experiences of the communities they serve?

The authors looked for information on how well youth collections reflect diversity but found little information to support commonly shared unconscious assumptions that some libraries were more likely to have diverse collections because of library type or community demographics. The authors had discussed possible research on how selector education or beliefs influenced juvenile collection diversity, but realized that the first step needed to be determining that significant differences in collections actually exist.

Diverse collections are important. Bernice Cullinan (1989) used the metaphors of a mirror and a window to describe two purposes for children's literature. Books mirror children's lives, reflecting their own experiences and reassuring children that their hopes, challenges, and dreams are shared by others. Books also create windows into the lives of others, allowing children to peek into other lives and other cultures, to vicariously experience life through another's eyes. A library collection that includes books with diverse characters and cultures subtly reaffirms young people's sense of self and the value of their culture while providing opportunities to expand their awareness and understanding of other viewpoints and cultures. How well do library collections in the United States provide those mirrors and windows for 
children and young adults when the characters are members of populations which have been discriminated against or disadvantaged?

\section{Literature Review}

According to Jaeger, Subramaniam, Jones, and Bertot (2011), racial and ethnic diversity have been the focus of library and information science (LIS) diversity research and education, as have efforts to diversify the profession. Jaeger et al. recommended that LIS diversity research and education include populations which may be discriminated against, disadvantaged, and underserved due to factors such as disability, geography, sexual orientation, and socioeconomic status. This study focuses on the extent to which members of three populations are represented in youth collections: members of minority racial and ethnic groups, individuals with disabilities, and individuals who identify as lesbian, gay, bisexual, transgender, queer, or questioning (LGBTQ).

Selecting appropriate terminology is a challenge when writing about diversity issues. Terms may be politically charged, may be rejected by the groups they are used to describe, and may change meaning over time. In this article, when discussing work done by other researchers, the authors use the source's terminology. For example, the same group may be described as Negro, Black, Afro-American, or African American depending on how that group was described in the source material. The authors followed the contemporary practice of using LGBTQ to describe individuals who identify as lesbian, gay, bisexual, transgender, and queer or questioning, but used LGB when discussing work focused on lesbian, gay, and bisexual populations. Following the 2010 usage of the United States Census Bureau, the authors use the terms “majority” or "non-Hispanic White” to represent the currently dominant racial/ethnic group in the United States, while the term “minority” represents members of other racial and ethnic groups.

Librarians have recognized the importance of diversity in library collections for at least half a century. The Freedom to Read Statement, adopted by the American Library Association and American Association of Publishers in 1953, states, "It is in the public interest for publishers and librarians to make available the widest diversity of views and expressions, including those that are unorthodox, unpopular, or 
considered dangerous by the majority” (para. 8). The ALA’s Policy on Diversity in Collection Development states that "Librarians have a professional responsibility to be inclusive, not exclusive, in collection development .... Access to all materials and resources legally obtainable should be assured to the user... This includes materials and resources that reflect a diversity of political, economic, religious, social, minority, and sexual issues” (American Library Association, 2013, B.2.1.11 ).

Despite this recognition that diversity is important in children’s literature and in library collections, both the library and education literature contain evidence that building diverse youth collections may be difficult. Although slightly over 16\% of the United States population was nonwhite in 1960 (Dodd, 1993), just a few years later, Larrick (1965) reported that, of over 5,000 books published for children between 1962 and 1964 that she examined, a mere 6.7\% included one or more Negroes. Larrick also noted that many of those books included Negroes only as a dark face in a crowd or with derogatory stereotypes. Decades later in the 2010 Census, non-Hispanic Whites were the majority population of the United States, but 36\% of the population indicated that they were members of racial and ethnic minorities (Humes, Jones, \& Ramirez, 2011). Although more than one-third of the population of the United States were members of racial and ethnic minorities, statistics from the Cooperative Children's Book Center (CCBC) showed that less than $10 \%$ of books published for children and teenagers in the United States during 2011 were by or about African Americans, American Indians, Asian/Pacific Island Americans, and Latinos (Cooperative Center for Children’s Books, n.d.).

Concerns about lack of racial and ethnic minority representation in youth literature are also evident in library science and education literature. In a study of middle-school genre fiction, Agosto, Hughes-Hassell, and Gilmore-Clough (2003) found that about 16\% of books published between 1992 and 2001 included at least one minority character in a significant role. Hughes-Hassell and Cox (2010) found that children's board books rarely include minorities, but when they do, frequently present them in inauthentic contexts. Kurz (2012) found that not quite 18\% of South Carolina Picture Book Award nominees featured a minority main character, none of them Latino, although more than $40 \%$ of the state's 
children are minorities and more than $7 \%$ were Latino.

Concerns about racial and ethnic diversity in youth literature go beyond the mere scarcity of titles. For example, Sims noted that middle-aged African Americans who had attended newly integrated schools in the mid-twentieth century often had "painful memories of having white schoolmates call him or her ‘Little Black Sambo’ or some equally demeaning epithet from classroom story hours” (Sims, 1983, p. 650). Sims stressed the importance of author's perspective as well as cultural authenticity, pointing out that even a book with a setting rife with poverty, drugs, and crime can emphasize cultural values such as "the strength and support to be found in human relationships” (Sims, 1983, p. 653). Yokoto (1983) pointed out that while an author writing about his or her own culture will naturally include cultural details in a story, it is possible for an author to gain sufficient understanding through research and close contact to write accurately about another culture. Yokoto also pointed out that a person who does not live in his or her birth culture may be able to write authentically of the experience of living in an adopted culture but not be able to write authentically of the birth culture. Caldwell, Kaye, and Mitten (2007) discussed both culturally authentic titles about American Indians and popular but problematic titles. For example, Caldwell et al. cited Susan Jeffers' Brother Eagle, Sister Sky as a problematic title, praising its environmental message but pointing out that it is based on a made-up speech by Duwamish Chief Seattle and has illustrations reflecting the cultures of the Plains rather than the Northwest Coast Duwamish people. Two books edited by Slapin and Seale (1992, 2005) used a combination of personal essays and annotated bibliographies to explain why many depictions of American Indians in youth books are inaccurate, offensive, and perpetuate harmful stereotypes; both books recommend many youth books which are accurate and authentic in their portrayal of American Indians. The problems of damaging stereotypes and lack of cultural authenticity are so extensive that college textbooks, such as Multicultural Literature and Response: Affirming Diverse Voices (Smolen \& Oswald, 2011) and Cultural Journeys: Multicultural Literature for Children and Young Adults (Gates \& Mark, 2006), have been published to introduce future teachers, librarians, and others preparing to work with young people to issues in selecting and using youth books about minority cultures. 
Individuals with disabilities are another population which may be discriminated against, disadvantaged, and underserved by libraries. Approximately 13\% of children and young adults in United States public schools were served under the Individuals with Disabilities Education Act (IDEA) during the 2008-09 school year, indicating a strong need for library collections to include books that mirror the experiences of these youth (Aud et al., 2011). The authors were unable to find statistics on the number of youth books published about individuals with disabilities, although they did note that Disabilities and Disorders in Literature for Youth (Crosetto, Garcha, \& Horan, 2009) included just over 500 youth titles, most published between 2000 and 2008.

Many librarians and educators have written about using books to help children and teenagers understand and accept individuals with disabilities. In a review of research studies, Anthony (1972) found that neither providing contact with nor information about individuals with disabilities consistently improved attitudes toward them, but that combinations of regular contact with and reading or viewing information about individuals with disabilities did improve attitudes. Smith-D’Arezzo (2003) found that encouraging elementary school children to read enjoyable and realistic books about children with disabilities can promote understanding, although she also stated that not all children will develop more accepting attitudes unless an adult provides some guidance. Prater, Dyches, and Johnstun (2006) encouraged educators to use books that include characters with learning disabilities to help children and young adults understand the challenges that disabled peers face and accept them as people first, rather than focusing on their differences. Rogers and Writt (2010) suggested that reading children's literature about disabilities helps education students learn about books to share with children and helps them learn about disabilities without intimidating jargon. Andrews (1998) encouraged librarians who are evaluating fiction about individuals with disabilities to look for a plot that does not center on the disability, but reveals aspects of the disability naturally through the storyline. Finally, Walling (2010) stressed that books about children with disabilities should present the disability as just one characteristic of a whole person who is involved in life, faces realistic problems, and is involved with others who do not have disabilities. 
A third population which may be discriminated against, disadvantaged, and underserved by libraries is people who identify as LGBTQ. Estimates of the number of LGBTQ individuals in the United States vary, but demographer Gary J. Gates (2011) used data from multiple surveys to estimate that 3.8\% of the United States population identifies as LGBTQ, while the 2010 Census showed that more than 110,000 same-sex couples in the United States are raising children (Lofquist, Lugaila, O’Connell, \& Feliz, 2012). Sexual orientation is a controversial topic in the United States; such controversial topics require extra diligence from librarians to ensure all children and young adults can find mirrors of themselves and their families in the collection.

Several studies conducted during the 1990s examined the extent to which libraries hold LGBTQ titles. A 1995 Library Journal survey of LGB issues in public and college libraries found "widespread, though not universal, inattention to gay book collections,” with half the libraries responding reporting fewer than 30 LGB titles held and 14\% that reported no LGB titles (Bryant, 1995, p. 37). Sweetland and Christensen (1995) compared holdings of LGB titles to a list of general titles selected from Publishers Weekly, finding that the general titles had significantly more OCLC holdings than the LGB titles even though both title lists had received approximately the same number of reviews. Spence $(1998,1999)$ conducted two studies of the catalogs of urban public library systems in the United States and Canada, one focusing on adult LGB titles and the other on young adult LGB fiction, finding that both the number of titles held and the number of copies held per capita varied greatly. Rothbauer and McKechnie (1999), investigating holdings of LGB young adult fiction in Canadian public libraries, also found a disparity in number of titles held. In recent years, LGBTQ materials have been widely discussed among librarians and educators; for example, Stringer-Stanback (2011) studied the relationship between holdings of LGBTQ non-fiction young adult materials and the adoption of county anti-discrimination policies in the Southeastern United States. The publication of Rainbow Family Collections (Naidoo, 2012) provided librarians with a guide to selecting and using children’s books with LGBTQ content. Interest in diverse youth literatures among researchers has been paralleled by the growth of book 
awards and other recognitions targeting specific groups. The ALA, its divisions, and its affiliates recognize the need to recognize and promote quality youth literature by and about racial and ethnic minorities, about people with disabilities, and about people who identify as LGBTQ. The Coretta Scott King Award, founded in 1969, recognizes excellence in children's and young adult books that "demonstrate an appreciation of African American culture and universal human values” (Ethnic and Multicultural Information Exchange Round Table, 1996-2013, para. 1). Titles are selected annually by the Coretta Scott King Book Award Committee, part of ALA's Ethnic and Multicultural Information Exchange Round Table (EMIERT). The Coretta Scott King Book Award Committee also periodically recognizes a new African American author or illustrator for children and young adults with the John Steptoe Award.

The Pura Belpre Award was established in 1996 to recognize children's and young adult literature that "best portrays, affirms, and celebrates the Latino cultural experience” (Association for Library Service to Children, 1996-2013, para. 1). The honored book must be by a Latino or Latina author or illustrator. The award is co-sponsored by the Association for Library Service to Children (ALSC) and the National Association to Promote Library and Information Services to Latinos and the Spanish-Speaking (REFORMA). The Belpre Award was given biennially until 2008; it is now an annual award.

In 2000-2001, the Asian Pacific American Library Association (APALA) established awards to recognize books about Asian Pacific Americans and their heritage (Asian Pacific American Library Association, 2010). The criteria focus on literary and artistic merit, and the guidelines encourage that nominated titles be by Asian Pacific Island Americans. Awards are presented biennially in several categories, ranging from picture book to adult, and the association may also name honor books.

The American Indian Library Association (AILA) presented the first AILA Youth Literature Awards in 2006 (American Indian Library Association (ca. 2006). The award committee is charged with identifying the best writing and illustrations by and about American Indians. The winning books must "present American Indians in the fullness of their humanity in the present and past contexts” ([linked criteria handout], para. 1). The AILA Awards are presented biennially in picture book, middle school, and 
young adult categories; the committee may also name honor books.

In remarks made at the first presentation of the Schneider Family Book Award, Schneider (2004) described the librarian at the Michigan Library for the Blind as her childhood hero and mentioned that during her school years in the 1950s, books and media rarely mentioned people with disabilities. Schneider and her family endowed the award in 2003 to recognize "a book that embodies an artistic expression of the disability experience for child and adolescent audiences” (American Library Association, 1996-2013b, para. 1). An ALA award jury selects three books annually, usually one each for younger children, middle grades, and teens. The award's guidelines state that winning books must portray a character living with a physical, mental, or emotional disability; the character does not have to be the protagonist but must be important to the story.

The Rainbow List is an annual bibliography of books for youth from birth to age 18 that reflect the LGBTQ experience (American Library Association, 1996-2013a). Titles are selected by a committee drawn from members of the Gay, Lesbian, Bisexual, and Transgender Round Table and the Social Responsibilities Round Tables of the ALA. Criteria include commendable literary quality and distribution in the United States during the previous 18 months; both fiction and nonfiction titles are eligible. The first Rainbow Book List was announced in 2008, with 45 titles published between 2005 and 2007. The initial committee noted that most of the titles were for teens because few titles had been published that were appropriate for children (Rainbow Books, 2009).

\section{Research Questions}

This research began with a very broad question: How well do library youth collections reflect the diverse families and life experiences of the communities they serve? Diversity can be viewed in many ways; the ALA Policy on Diversity in Library Collections lists "political, economic, religious, social, minority, and sexual issues” (American Library Association, 2013, section B.2.1.11). The authors decided to focus on four questions in measuring the extent to which youth collections include representations of diverse families and life experiences: 
- To what extent do libraries in the United States collect youth literature that includes characters from racial and ethnic minorities? Characters with physical, learning, and emotional disabilities? Characters who identify as LGBTQ?

- Is there any difference in representations of diversity in youth collections in academic, public, and school libraries?

- Is there any difference in representations of diversity in youth collections by region of the United States?

- Is there any difference in representations of diversity in public library youth collections by library collection size? By expenditures on collections?

Initially, the authors also hoped to address a fifth question: Is there any difference in representations of diversity in public library youth collections by racial diversity, ethnic diversity, or median household income of the community served? However, the authors soon discovered that while such demographic data is readily available in the United States Census, matching library holdings to census data is complicated because public libraries may serve a city, a county, or a group of counties.

\section{Research Method}

The authors used the list-checking method to determine the extent to which libraries collect youth literature that includes characters from racial and ethnic minorities, characters with disabilities, and characters who identify as LGBTQ. As Porta and Lancaster (1988) noted, the first problem in evaluating collections by list checking is the selection or creation of a bibliography that represents the types of books the library's users are likely to seek. Criteria for the lists included:

- Titles had been positively reviewed or included on recommended lists

- $\quad$ Titles were appropriate for birth to age 18

- Titles had been evaluated for cultural authenticity and avoidance of stereotypes

- Titles ranged from widely to less commonly held

- $\quad$ Titles were published between 2000 and 2009 
The restriction on publication date was intended to emphasize relatively recent collection decisions and to minimize the likelihood that checklist titles had been weeded from library collections.

The authors were unable to locate an appropriate checklist for racial and ethnic diversity, so they developed a checklist. The basis of the racial/ethnic diversity checklist was titles recognized by professional library associations for excellence in portraying minority cultures in youth literature, including titles which won or were named as honor books for the Coretta Scott King Award, the John Steptoe Award, the Pura Belpre Award, the APALA Award, and the AILA Award. Because one goal of the checklist was to include a broad spectrum of titles, from widely to less commonly held, the authors used Multicultural Review to identify additional titles for the racial/ethnically diverse checklist. Multicultural Review was founded in 1991 to foster a "better understanding of ethnic, racial and religious diversity" (Smith, 2009, para. 16) among educators and librarians; most book reviewers were either members of racial and ethnic minorities or had an academic background in the culture of the book being reviewed. In addition, Multicultural Review explicitly addressed issues of cultural authenticity in its book reviews. The authors added titles from the children's review section to the checklist. The authors did not add a title when the reviewer noted problems with cultural authenticity, the reviewer specifically stated that the title was not recommended, the book was not published between 2000 and 2009, or when the authors were not able to determine which racial/ethnic group was portrayed in the book.

The authors assigned each title to a broad racial/ethnic grouping, using the award list the title appeared on or the race/ethnicity mentioned in the Multicultural Review book review. Some titles added to the checklist from Multicultural Review were assigned to two racial/ethnic groups when the review mentioned both groups. The authors made no attempt to ensure that the checklist included equal representation of each group; the checklist reflects the availability of culturally authentic children's and young adult books distributed in the United States from 2000 to 2009. Given that broad groupings like Asian Pacific Islander American reflect many cultures, from Iraqi Americans to Japanese Americans, the value of any data analysis made based on such broad groupings would be limited. Table 1 shows the 
number of titles from each broad group on the racial/ethnic checklist.

\begin{tabular}{llr}
\hline Table 1. Titles per checklist. & \multicolumn{2}{c}{ No. } \\
\hline \multirow{3}{*}{ Checklist } & Subgroup & Titles \\
\hline Racial/Ethnic & All Titles & 964 \\
& African American & 422 \\
& American Indian & 72 \\
& Asian/Pacific Island American & 278 \\
& Hispanic/Latino & 209 \\
\hline Disabilities & All Titles & 334 \\
& Emotional & 117 \\
& Mental & 115 \\
& Physical & 102 \\
\hline LGBT & All Titles & 116 \\
\hline Major & & \\
Awards & All Titles & 30 \\
& Caldecott & 10 \\
& Newbery & 10 \\
& Printz & 10 \\
All Checklists & & 1421 \\
\hline
\end{tabular}

Note: Some titles were assigned to multiple categories.

The second checklist of titles portraying people with disabilities was developed from two sources, the Schneider Family Book Award and the selective bibliography Disabilities and Disorders in Literature for Youth (Crosetto, Garcha, \& Horan, 2009). Titles for the bibliography were selected from positive reviews in a variety of standard sources; only titles published during the decade from 2000 to 2009 were included on the disabilities checklist. Because the authors relied heavily on a bibliography published in 2008, the disability title list includes few titles published during late 2008 or during 2009.

The third checklist, titles portraying people who identify as LGBTQ, is composed of titles from the Rainbow Book List. The earliest Rainbow List began with titles published in 2005, so the LGBTQ list includes no titles from the first half of the decade. While Naidoo's Rainbow Family Collections (2012) would also be an excellent source of titles for children ages birth to 11, it was published after the authors completed the data collection for this project.

The authors used a fourth checklist, major awards, to identify libraries that actively collect youth 
literature. For the purpose of this research, the authors defined a library that actively collects youth literature as one that held at least 20\% of the Caldecott Medal, Newbery Medal, and Printz Medal winning titles from 2000 and 2009. As these three medals are awarded for best American picture book for children, most distinguished book for children published in America, and excellence in young adult literature, any United States library that actively collects youth literature should hold some of these titles. While $20 \%$ may seem a low threshold, the authors did not want to eliminate school libraries which serve a limited age range.

After developing the four checklists, the authors searched each title in OCLC WorldCat to determine library holdings. All holding symbols were copied into a spreadsheet for each title. Many titles had multiple records, reflecting hardcover and paperback editions, audio books, video recordings based on the book, Braille editions, and editions in multiple languages. Since content, rather than format or language, was of primary importance for this research, holdings were recorded for every OCLC record. Holding symbols were de-duplicated, then transferred to an Access database. The database included 11,394 unique holdings symbols.

Using checklists is a standard method of assessing library collections, but libraries sometimes need a method to express their collection goals and to compare their collections to those of similar institutions. In the 1980s, the Research Libraries Group (RLG) developed a six-level Conspectus scale to rate library collections; the scale ranges from 0 for out-of-scope to 5 for comprehensive collecting (Bushing, 1997). Early Conspectus rankings were based solely on librarians’ professional judgment. White (1995) proposed brief tests of collection strength as a method of reducing the subjectivity of Conspectus rankings. His brief tests relied on a subject expert developing title lists ranked from most likely to least likely to be held by a library. By obtaining OCLC holding counts for each title on the list, White could establish an objective scale for comparing libraries. Extensive testing showed that they were cumulative; a library that held at least half of the titles at a given level would also hold at least half of the items at all lower levels. Later tests by Twiss (2001) and Lesniaski (2004) demonstrated that results from White’s brief-test method were replicable and consistent with expectations in both academic and public libraries. Given a list of books on a 
specific topic, OCLC holdings could be used to establish an objective scale for assigning Conspectus levels.

After de-duplicating the OCLC holdings for all checklist titles, the authors created a chart matching OCLC holdings ranges with RLG Conspectus levels. Titles were ranked from most to least commonly held, then the ranges were divided into five levels: minimal, basic, resource, research, and comprehensive. Each level included $20 \%$ of the checklist titles. The authors used this scale to assign each library a Conspectus level for youth racial/ethnic diversity, youth disability diversity, and youth LGBTQ diversity. Following White's procedures, a library was assigned to the highest Conspectus ranking for which it held at least half of the titles. Table 2 shows the Conspectus levels with the corresponding OCLC holdings range.

\begin{tabular}{llll}
\hline \multicolumn{3}{l}{ Table 2. Conspectus levels with corresponding OCLC holding ranges. } \\
\hline & $\begin{array}{l}\text { Race/Ethnicity } \\
\text { Conspectus Levels }\end{array}$ & $\begin{array}{l}\text { Disability } \\
\text { Checklist }\end{array}$ & $\begin{array}{l}\text { LGBTQ } \\
\text { Checklist }\end{array}$ \\
\hline & & more than & more than \\
L-1 Minimal & more than 1480 & 1100 & 1000 \\
L-2 Basic & $900-1480$ & $600-1100$ & $730-1000$ \\
L-3 Instruction/Study & $640-899$ & $401-599$ & $541-729$ \\
L-4 Research & $420-639$ & $280-400$ & $330-540$ \\
& & & fewer than \\
L-5 Comprehensive & Less than 420 & Less than 280 & 330 \\
\hline
\end{tabular}

The authors next queried the database to identify OCLC symbols for libraries that met the $20 \%$ threshold for actively collecting youth literature. Student workers looked up these holding symbols (OCLC, 2013) and recorded the symbol, library name, street address, city, state, zip code, country, and institution type in the database. The authors eliminated libraries that were outside the United States or which were not clearly identified as academic, public, school, or votech/community colleges in the OCLC listing. Libraries identified as either academic or votech/community college in the OCLC listing were categorized as academic libraries for this project. By the conclusion of data collection, the authors had identified 5,004 United States academic, public, and school libraries that actively collect youth literature.

Each library that actively collected youth literature was assigned to a region based on the Census Bureau regions: Northeast, Midwest, South, and West (United States Census Bureau, n.d.). To determine 
the extent to which libraries collect youth literature that includes characters from racial and ethnic minorities, characters with disabilities, and characters who identify as LGBTQ, the authors calculated the average number of titles held for each type of library by region for each checklist. The authors also computed a one-way ANOVA (F) comparing number of each checklist titles held by type of library and a one-way ANOVA comparing number of checklist titles held by region of the United States to determine whether a there is a difference in representations of diversity in youth collections by type of library or by region of the United States.

To enable comparisons between libraries with similar collection sizes and similar collection budgets, the authors recorded the number of print volumes held and total collection expenditures for each public library from the Public Library Survey 2009 (Manjarrez et al., 2011). The authors manually matched OCLC symbols to the Public Library Data Survey data by comparing library names and addresses. Although the authors had identified 2,507 public libraries that actively collected youth literature, the authors were only able to match 2,264 public library OCLC symbols to libraries in the Public Library Data Survey. The most common problem in matching OCLC holding symbols to the Public Library Data Survey was that some OCLC symbols were for regional library systems or cooperatives, even though they were listed as public libraries in the OCLC listing. Another common problem was the existence of multiple possible matches in the same town, but none that closely matched the library name in the OCLC listing. After matching OCLC symbols and library names, the authors computed the coefficient of determinations (r2) for each of the checklists to determine whether a relationship exists between collection size and youth diversity holdings or between collection expenditures and youth diversity holdings.

Finally, the authors decided to include limited demographic information for a few public libraries that had strong holdings of titles on the three diversity checklists. The authors recorded the total population, the number who identified themselves as White with no other race indicated, and the number who identified themselves as Hispanic/Latino in the United State Census (2010) for each library’s service area. Determining which demographic data should be matched to each OCLC holding symbol was complicated 
as some libraries serve cities, some counties, and some multi-county consortia. The authors checked each library's website to determine its service area, then extracted data for the relevant cities and counties from the appropriate census tables.

\section{Results and Discussion}

The authors identified 5,002 academic, public, and school libraries in the United States that actively collect youth literature; these institutions held an average of 158.1 titles from the 964 titles on the race/ethnicity checklist, 45.7 titles from the 334 titles on the disability checklist, and 24.9 titles from the 116 titles on the LGBTQ checklist. The number of titles held varied both by type of library and by region; see Table 3 for the average number and range of titles held.

\begin{tabular}{|c|c|c|c|c|c|c|c|c|c|c|}
\hline \multirow{2}{*}{$\begin{array}{l}\text { Library } \\
\text { Type }\end{array}$} & \multirow[b]{2}{*}{ Region } & \multirow{2}{*}{$\begin{array}{c}\text { No. } \\
\text { Libraries }\end{array}$} & \multicolumn{2}{|c|}{$\begin{array}{c}\text { Major Awards } \\
(n=30)\end{array}$} & \multicolumn{2}{|c|}{$\begin{array}{c}\text { Race/Ethnic } \\
(n=964)\end{array}$} & \multicolumn{2}{|c|}{$\begin{array}{l}\text { Disability } \\
(n=334)\end{array}$} & \multicolumn{2}{|c|}{$\begin{array}{c}\text { LGBT } \\
(n=116)\end{array}$} \\
\hline & & & Mean & Range & Mean & Range & Mean & Range & Mean & Range \\
\hline \multirow[t]{4}{*}{ Academic } & Northeast & 327 & 21.27 & $6-30$ & 104.54 & $1-780$ & 20.61 & $0-156$ & 8.87 & $0-109$ \\
\hline & Midwest & 469 & 21.74 & $6-30$ & 119.43 & $1-808$ & 22.08 & $0-148$ & 9.29 & $0-101$ \\
\hline & South & 592 & 20.45 & $6-30$ & 100.8 & $0-736$ & 20.73 & $0-143$ & 7.39 & $0-95$ \\
\hline & West & 264 & 19.89 & $6-30$ & 109.8 & $0-687$ & 18.56 & $0-126$ & 9.21 & $0-106$ \\
\hline \multirow[t]{4}{*}{ Public } & Northeast & 163 & 22.99 & $6-30$ & 348.4 & $2-888$ & 91.72 & $1-316$ & 43.43 & $0-128$ \\
\hline & Midwest & 1095 & 21.04 & $6-30$ & 193.08 & $2-929$ & 56.37 & $0-290$ & 22.85 & $0-135$ \\
\hline & South & 726 & 19.67 & $6-30$ & 210.28 & $5-864$ & 52.04 & $0-259$ & 19.74 & $0-117$ \\
\hline & West & 523 & 22.35 & $6-30$ & 246.64 & $1-893$ & 60.69 & $0-252$ & 29.48 & $0-130$ \\
\hline \multirow[t]{4}{*}{ School } & Northeast & 46 & 11.48 & $6-30$ & 75.02 & $11-655$ & 20.91 & $1-182$ & 8.87 & $0-70$ \\
\hline & Midwest & 512 & 12.53 & $6-30$ & 71.43 & $1-684$ & 22.82 & $1-200$ & 5.6 & $0-90$ \\
\hline & South & 96 & 9.8 & $6-30$ & 70.73 & $11-767$ & 17.43 & $1-259$ & 3.6 & $0-74$ \\
\hline & West & 189 & 12.9 & $6-30$ & 82.03 & $6-810$ & 22.94 & $1-249$ & 6.87 & $0-89$ \\
\hline
\end{tabular}

Note: There was a significant difference among type of library in holdings of titles on the race/ethnicity $(\mathrm{F}(2,4999)=328.29$, $\mathrm{p}<.05)$, disability $(\mathrm{F}(2,4999)=493.68, \mathrm{p}<.05)$, and LGBTQ $(\mathrm{F}(2,4999)=335.81, \mathrm{p}<.05)$ checklists. There was a significant difference among regions in holdings of titles on the race/ethnicity $(F(3,4998)=8.46, p<.05)$, disability $(F(3,4998)=3.71$, $p<.05)$, and LGBTQ (F(3, 4998)=15.28, $\mathrm{p}<.05$ ) checklists.

The authors were surprised to note that three academic institutions held no titles from the race/ethnicity checklist. None of these three libraries held more than one-third of the titles from the major award checklist, and none held more than two titles each from the disability and LGBTQ checklists. This suggests that these libraries, and perhaps other academic libraries, may have very small youth literature 
collections. Some of the academic libraries may limit their youth collections to titles that won a specific award, but have a few titles in their general collections which were included on the diversity checklists as appropriate for young adults.

Forty academic libraries and eight public libraries held no titles from the disability checklist. With the exception of the University of Wisconsin-Green Bay, the academic libraries that held no titles from the disability list also held less than $0.5 \%$ of the titles on the race/ethnicity checklist and five or fewer titles from the LGBTQ checklist, a finding which suggests that these libraries may limit their youth collections to titles that win specific awards. The University of Wisconsin-Green Bay was unusual because it held 142 titles from the race/ethnicity checklist but no titles from the disability checklist. The authors speculate that the university may have faculty members expressing an interest in racially/ethnically diverse titles, but not specifically requesting titles or assigning students to read youth titles about individuals with disabilities.

The authors were also surprised to note that eight of the public libraries held no titles on the disability checklist. All eight also had relatively few holdings from the other diversity checklists and held less than half of the major award checklist titles. Three of the eight spent less than $\$ 10,000$ on collections, according to the Public Library Survey 2009; the authors were unable to match the other five libraries to a library in the Public Library Survey database. While limited budgets are one possible explanation for the lack of disability checklist titles at these eight libraries, other possibilities include inconsistencies in attaching holdings to OCLC records, reliance on floating collections within a public library system to supply some needs, and weeding or loss of books.

Fifteen percent of the libraries held none of the 116 titles on the LGBTQ checklist. Finding that 237 academic libraries, 326 public libraries, and 207 school libraries held none of the LGBTQ checklist titles is concerning. While sexual orientation is a controversial topic, the Freedom to Read Statement specifically recognizes the need for librarians "to make available the widest diversity of views and expressions, including those that are unorthodox, unpopular, or considered dangerous by the majority” (American Library Association \& Association of American Publishers, 1953-2004, para. 8). Some of the 770 libraries 
that hold no titles from the LGBTQ checklist may have very limited collection budgets or restrict their youth collections to titles that win specific awards; however, 31 of the libraries held at least $10 \%$ of the 964 titles on race/ethnicity checklist, and 35 held at least 20\% of the 334 titles on the disability checklist. Limited budgets cannot be the only reason some libraries have no holdings from the LGBTQ checklist. The authors ranked the libraries by number of titles held from the race/ethnicity checklist, the disability checklist, and the LGBTQ checklist; the top ten holding libraries for each checklist are listed in Table 4 with the number of titles held and ranking for each checklist. With one exception, libraries that ranked in the top ten for holdings of one checklist also ranked in the top 100 on the other two checklists. Brooklyn Public Library was a puzzling exception; it ranked ten on holdings of the LGBTQ checklist titles, 84 on holdings of the disability checklist titles, but only 288 on holdings of the race/ethnicity checklist titles. No academic libraries ranked in the top ten, and only one school library did. The school library is Pasco County School System, Florida; the authors searched for the website and discovered that Pasco is a school district with 84 schools (Pasco, 2013). Although Pasco County School System ranked in the top ten on disability checklist holdings, it was not in the top 50 for either race/ethnicity checklist or LGBTQ checklist holdings, suggesting that one or more of the district's librarians makes collecting books about individuals with disabilities a high priority. Four of the public libraries ranked in the top ten on all three youth diversity checklists. 


\begin{tabular}{|c|c|c|c|c|c|c|c|c|c|c|c|}
\hline \multirow[b]{2}{*}{ Region } & \multirow{2}{*}{ Library } & \multicolumn{2}{|c|}{ Population Served } & \multicolumn{2}{|c|}{ Collections } & \multicolumn{2}{|c|}{$\begin{array}{l}\text { Race/Ethnicity } \\
\qquad(n=964)\end{array}$} & \multicolumn{2}{|c|}{$\begin{array}{l}\text { Disability } \\
\text { (n=334) }\end{array}$} & \multicolumn{2}{|c|}{$\begin{array}{l}\text { LGBTQ } \\
(n=116)\end{array}$} \\
\hline & & $\begin{array}{r}\% \text { White } \\
\text { Alone }\end{array}$ & \% Hispanic & Print Volumes & $\begin{array}{l}\text { Expenditures } \\
\text { (\$) }\end{array}$ & No. & Rank & No. & Rank & No. & Rank \\
\hline Midwest & $\begin{array}{l}\text { ALLEN CNTY PUB LIBR } \\
\text { Ft Wayne, IN }\end{array}$ & 79.3 & 6.5 & $3,374,517$ & $3,281,970$ & 929 & 1 & 290 & 2 & 92 & 10 \\
\hline & $\begin{array}{l}\text { BIRMINGHAM-JEFFERSON PUB } \\
\text { LIBR }\end{array}$ & & & & & & & & & & \\
\hline Northeast & $\begin{array}{l}\text { BROOKLYN PUB LIBR } \\
\text { Brooklyn, NY }\end{array}$ & 42.8 & 19.8 & $3,943,126$ & $7,448,824$ & 442 & 288 & 149 & 84 & 92 & 10 \\
\hline Northeast & $\begin{array}{l}\text { CARNEGIE LIBR OF PITTSBURGH } \\
\text { Pittsburgh, PA }\end{array}$ & 81.5 & 1.6 & $1,566,561$ & $3,003,292$ & 703 & 92 & 183 & 51 & 97 & 9 \\
\hline Midwest & $\begin{array}{l}\text { CHICAGO PUB LIBR } \\
\text { Chicago, IL }\end{array}$ & 45 & 28.9 & $5,295,965$ & $10,187,665$ & 869 & 7 & 250 & 13 & 103 & 2 \\
\hline South & Houston, TX & 56.6 & 40.8 & $1,940,144$ & $4,098,703$ & 864 & 9 & 227 & 22 & 75 & 32 \\
\hline Midwest & $\begin{array}{l}\text { HENNEPIN CNTY LIBR } \\
\text { Minnetonka, MN }\end{array}$ & 74.4 & 6.7 & $4,417,865$ & $6,910,200$ & 891 & 3 & 208 & 33 & 104 & 1 \\
\hline & INFOSOUP (NE WI PUB LIBR) & & & & & & & & & & \\
\hline Midwest & Appleton, WI & 92.8 & 2.7 & 326,112 & 532,980 & 792 & 38 & 269 & 5 & 90 & 10 \\
\hline South & $\begin{array}{l}\text { Jacksonville Public Library } \\
\text { Jacksonville, FL } \\
\text { JEFFERSON CNTY PUB LIBR }\end{array}$ & 60.9 & 7.6 & $2,627,949$ & $3,738,487$ & 864 & 9 & 253 & 11 & 83 & 26 \\
\hline West & $\begin{array}{l}\text { Lakewood, CO } \\
\text { KING CNTY LIBR SYST }\end{array}$ & 88.4 & 14.3 & $1,065,523$ & $3,821,000$ & 765 & 56 & 189 & 47 & 101 & 3 \\
\hline West & Issaquah, WA & 68.7 & 8.9 & $3,084,584$ & $12,567,119$ & 893 & 2 & 252 & 24 & 96 & 6 \\
\hline
\end{tabular}




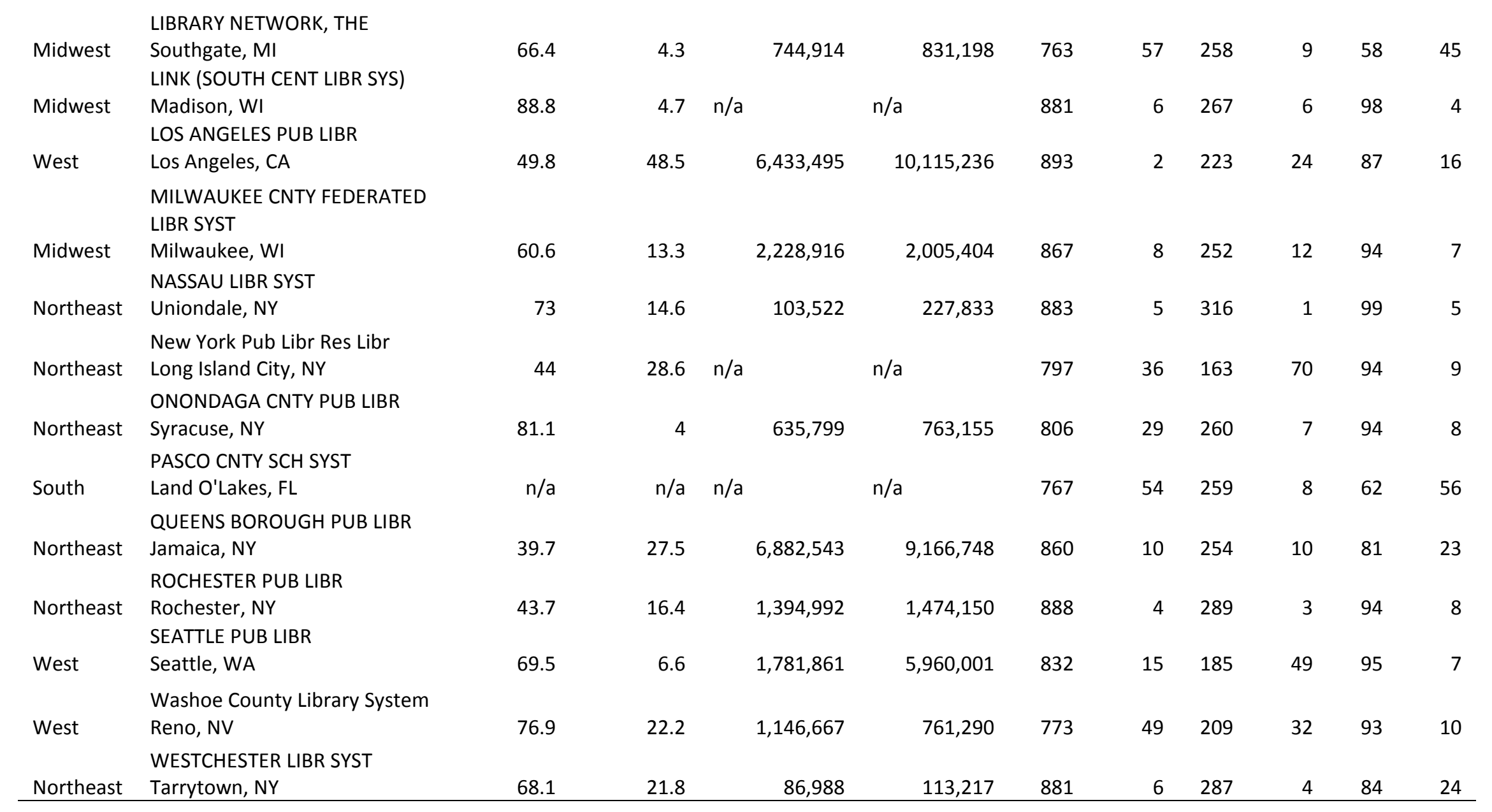

Note: Libraries holding the same number of titles for a checklist are ranked identically. 
Examining the service area of the four libraries that ranked in the top ten on all three youth diversity checklists revealed a problem with relying on OCLC WorldCat holdings to assess library collections. Some OCLC holding symbols are for multi-branch public library systems. For example, Allen County Public Library (2005) consists of the main library and 13 branches. LINK is the shared catalog for the South Central Library System (2013) which serves a 7-county area of Wisconsin. The Nassau Library System (2007-2012) includes 54 public libraries in Nassau County, New York, and Rochester Public (City of Rochester, n.d.) has ten locations. OCLC WorldCat holdings indicate that children and teenagers at each of these four libraries have access to diverse youth collections through the library catalog, but the data do not reveal the number of copies held or their distribution among branches. As Spence $(1998,1999)$ noted in his studies of LGBTQ materials in the late 1990s, by looking at both number of titles held and number of copies held per capita, librarians can gain a better picture of how accessible materials on a particular topic are in a library system.

After comparing holdings of the diversity checklist titles by geographic region and type of library, the authors focused on holdings by public libraries. Examining the number of diversity checklist titles held per 10,000 volumes held revealed a mild relationship between race/ethnicity titles ( $r 2=0.22$ ), disability titles (r2=0.22), and LGBTQ titles (r2=0.22) held and collection size. Larger collections tended to have more titles from the diversity checklists. On average, the number of race/ethnicity checklist titles held increased 18.4 for every additional 10,000 volumes in the collection, while the number of disability titles increased 0.4 and the number of LGBTQ titles increased by 0.3 per additional 10,000 volumes in the collection. The number of titles on each checklist varied considerably, so it is not appropriate to make comparisons among checklists. As can be seen from the data in Table 5, which shows average checklist holdings by collection size, the number of volumes held is not a perfect predictor of diversity title holdings. The average number of diversity titles held by libraries with very small collections (under 5,000 volumes) and very large collections (over five million titles) do not fit the general rule of larger collections having more diversity checklist titles. The authors examined the libraries with fewer than 5,000 volumes and noted 
that this group includes a consortium with many more diversity titles than the other six libraries in the group, skewing the average holdings for the very small libraries group. The libraries within that consortium have separate holding symbols, leading the authors to speculate that the consortium collection consists of last copies, professional titles, or other titles that supplement the member library collections. The authors also examined the libraries with over five million volumes, noting that the number of race/ethnicity checklist titles held ranged from 250 to 893, disability titles from 77 to 250, and LGBTQ titles from 45 to 133, but did not identify any possible reason for the wide disparity in diversity checklist holdings.

\begin{tabular}{|c|c|c|c|c|c|}
\hline \multicolumn{6}{|c|}{ Major } \\
\hline No. Print Volumes & $\begin{array}{r}\text { No. Public } \\
\text { Libraries }\end{array}$ & $\begin{array}{l}\text { Award } \\
(n=30)\end{array}$ & $\begin{array}{r}\text { Race/Ethnicity } \\
(n=964) \\
\end{array}$ & $\begin{array}{r}\text { Disability } \\
(\mathrm{n}-334) \\
\end{array}$ & $\begin{array}{r}\text { LGBTQ } \\
(\mathrm{n}=116) \\
\end{array}$ \\
\hline Less than 5,000 & 7 & 17.71 & 134.29 & 33.71 & 12.29 \\
\hline 5,000 to 9,999 & 64 & 12.39 & 41.45 & 13.27 & 2.30 \\
\hline 10,000 to 24,999 & 414 & 14.12 & 40.31 & 13.90 & 2.38 \\
\hline 25,000 to 49,999 & 429 & 19.00 & 84.29 & 26.70 & 6.72 \\
\hline 50,000 to 99,999 & 443 & 22.76 & 174.23 & 49.34 & 18.11 \\
\hline 100,000 to 499,999 & 707 & 24.57 & 342.38 & 86.84 & 40.38 \\
\hline 500,000 to 999,999 & 115 & 26.10 & 507.62 & 126.65 & 62.11 \\
\hline \multicolumn{6}{|l|}{$1,000,000$ to } \\
\hline $2,499,999$ & 64 & 27.25 & 560.66 & 143.64 & 74.67 \\
\hline \multicolumn{6}{|l|}{$2,500,000$ to } \\
\hline $4,999,999$ & 14 & 29.14 & 710.86 & 180.07 & 103.79 \\
\hline $5,000,000$ or more & 7 & 28.86 & 624.71 & 168.86 & 83.00 \\
\hline Overall Mean & -- & 21.05 & 219.33 & 58.31 & 24.67 \\
\hline
\end{tabular}

The authors also found a mild relationship between expenditures on public library collections and number of race/ethnicity titles (r2=0.27), disability titles (r2=0.27), and LGBTQ titles ( $\mathrm{r} 2=0.3$ ) titles held. Libraries that spend more money on collections tend to hold more titles from the diversity checklists. On average, the number of race/ethnicity checklist titles held increased by 108.3, the number of disability titles increased by 2.7, and the number of LGBTQ titles increased by 1.6 per $\$ 100,000$ spent on collections. Table 6 shows average checklist holdings by 2009 collection expenditures.

Table 6. Mean public library holdings of checklist titles by 2009 collection expenditures. 
Diverse Population, Diverse Collection? Page 23 of 32

\begin{tabular}{lrrrrr}
$\begin{array}{l}\text { Expenditures (in } \\
\text { dollars) }\end{array}$ & $\begin{array}{r}\text { No. of } \\
\text { Libraries }\end{array}$ & $\begin{array}{r}\text { Mwajor } \\
(\mathrm{n}=30)\end{array}$ & $\begin{array}{r}\text { Racial/Ethnic } \\
(\mathrm{n}=964)\end{array}$ & $\begin{array}{r}\text { Disability } \\
(\mathrm{n}=334)\end{array}$ & $\begin{array}{r}\text { LGBTQ } \\
(\mathrm{n}=116)\end{array}$ \\
Less than 5,000 & 87 & 11.48 & 24.40 & 8.11 & 0.85 \\
5,000 to 9,999 & 158 & 13.11 & 32.74 & 10.51 & 1.70 \\
10,000 to 24,999 & 349 & 15.95 & 51.94 & 17.09 & 2.77 \\
25,000 to 49,999 & 314 & 19.41 & 90.79 & 28.67 & 6.75 \\
50,000 to 99,999 & 307 & 21.66 & 148.09 & 42.47 & 12.99 \\
100,000 to 499,999 & 676 & 24.31 & 287.78 & 74.76 & 32.86 \\
500,000 to 999,999 & 189 & 26.40 & 479.92 & 120.22 & 61.96 \\
1,000,000 to & & & & & \\
2,499,999 & 112 & 25.85 & 507.85 & 129.38 & 65.44 \\
2,500,000 to & & & & & \\
4,999,999 & 46 & 27.70 & 536.57 & 136.61 & 72.80 \\
5,000,000 or more & 26 & 28.81 & 694.92 & 177.19 & 100.08 \\
Overall Mean & -- & 21.08 & 213.9 & 56.98 & 24.13 \\
\hline
\end{tabular}

The authors looked at the Conspectus rankings of each public library to develop a better understanding of the strength of collections by library expenditures. As Table 7 shows, only 22 public libraries ranked at level 5 on the race/ethnicity conspectus, only five on the disability conspectus, and only 20 on the LGBTQ conspectus. Level 5 represents a comprehensive collection, where the library attempts to acquire every title available on a given topic, so it is unsurprising that only a few libraries achieve this rating. Level 0, on the other hand, represents an out-of-scope collection, an area in which the library does not attempt to collect and holds very few of the most commonly held titles. The authors were concerned by the number of libraries with level 0 ratings on the three youth diversity Conspectus scales. While it is understandable that a library spending less than $\$ 5,000$ a year will not be able to purchase many youth diversity titles, it is disturbing to find that so many libraries, including many that spend more than $\$ 100,000$ annually on collections, did not achieve a minimal rating on the youth diversity conspectus scales. The standard for a level 1 minimal collection is holding at least half of the level 1 titles, so a library would need to hold at least 95 titles from level 1 of race/ethnicity checklist, at least 33 titles from level 1 of the disability checklist, and at least 13 titles from level 1 of the LGBTQ checklist to be rated as having a minimal collection in that area. All of these libraries were identified as actively collecting youth literature based on 
OCLC holdings of major award winners, but it is possible that some are inconsistent in setting holdings in OCLC, others stopped setting OCLC holdings during the last decade, and some have strict weeding criteria based on age or circulation resulting in removal of older titles from their youth collections. It seems likely, however, that some of these libraries simply do not make collecting youth diversity literature a priority. 


\begin{tabular}{|c|c|c|c|c|c|c|c|c|c|c|c|c|c|c|c|c|c|c|}
\hline \multirow[b]{2}{*}{ Expenditures (in dollars) } & \multicolumn{6}{|c|}{ Race/Ethnicity Conspectus Levels } & \multicolumn{6}{|c|}{ Disability Conspectus Levels } & \multicolumn{6}{|c|}{ LGBTQ Conspectus Levels } \\
\hline & L-0 & L-1 & $\mathrm{L}-2$ & L-3 & L-4 & $\mathrm{L}-5$ & $\mathrm{~L}-0$ & L-1 & $\mathrm{L}-2$ & L-3 & $\mathrm{L}-4$ & $\mathrm{~L}-5$ & $\mathrm{~L}-0$ & L-1 & $\mathrm{L}-2$ & L-3 & L-4 & L-5 \\
\hline Less than 5,000 & 86 & 0 & 0 & 0 & 0 & 0 & 86 & 0 & 0 & 0 & 0 & 0 & 86 & 0 & 0 & 0 & 0 & 0 \\
\hline 5,000 to 9,999 & 157 & 0 & 0 & 0 & 0 & 0 & 156 & 1 & 0 & 0 & 0 & 0 & 157 & 0 & 0 & 0 & 0 & 0 \\
\hline 10,000 to 24,999 & 345 & 2 & 1 & 0 & 0 & 0 & 347 & 1 & 0 & 0 & 0 & 0 & 347 & 0 & 1 & 0 & 0 & 0 \\
\hline 25,000 to 49,999 & 293 & 19 & 2 & 0 & 0 & 0 & 293 & 20 & 1 & 0 & 0 & 0 & 309 & 4 & 0 & 1 & 0 & 0 \\
\hline 50,000 to 99,999 & 239 & 60 & 5 & 1 & 2 & 0 & 225 & 79 & 1 & 0 & 2 & 0 & 277 & 18 & 7 & 3 & 2 & 0 \\
\hline 100,000 to 499,999 & 261 & 189 & 141 & 55 & 28 & 2 & 250 & 356 & 59 & 7 & 1 & 3 & 343 & 141 & 106 & 69 & 15 & 2 \\
\hline 500,000 to 999,999 & 28 & 19 & 30 & 65 & 44 & 3 & 26 & 69 & 78 & 11 & 4 & 1 & 35 & 17 & 36 & 55 & 46 & 0 \\
\hline $1,000,000$ to $2,499,999$ & 24 & 7 & 8 & 16 & 51 & 6 & 25 & 19 & 40 & 22 & 5 & 1 & 29 & 9 & 11 & 10 & 49 & 4 \\
\hline $2,500,000$ to $4,999,999$ & 9 & 5 & 6 & 3 & 18 & 5 & 6 & 15 & 12 & 8 & 5 & 0 & 11 & 3 & 7 & 1 & 18 & 6 \\
\hline $5,000,000$ or more & 1 & 0 & 2 & 2 & 15 & 6 & 1 & 1 & 9 & 9 & 6 & 0 & 1 & 0 & 1 & 2 & 14 & 8 \\
\hline TOTAL & 1443 & 301 & 195 & 142 & 158 & 22 & 1415 & 561 & 200 & 57 & 23 & 5 & 1595 & 192 & 169 & 141 & 144 & 20 \\
\hline
\end{tabular}

NOTE: L-0 = Out of Scope, L-1 = Minimal, L-2 = Basic, L-3 = Instructional/Study, L- 4 = Research, L-5 = Comprehensive 


\section{Implications for Collection Development and Assessment}

The first finding of this study should not surprise any librarian who understands the basics of collection development and assessment; the authors found significant differences between academic, public, and school libraries in the extent to which they collect youth literature that reflects the diverse families and life experiences of members of racial and ethnic minorities, individuals with disabilities, and people who identify as LGBTQ. Library collections are built to meet the needs of their users. Table 2 shows that, in every region of the United States, public libraries collected a greater percentage of the checklist titles than either academic or school libraries. Both public and school libraries collect youth materials to support recreational reading and information needs, but public libraries collect for all age groups while school libraries often supported narrow age ranges. Academic libraries typically collect youth literature to support teacher education and other programs preparing professionals to work with youth, so the youth collections tend to be small collections of exemplary materials rather than the broader collections of school and public libraries. Librarians must consider the library’s mission and population served when selecting and using checklists to assess youth literature collections.

The second finding, that there are significant regional variances in representations of diversity in youth collections, is intriguing but must be considered in relation to population distribution. For example, Table 2 shows that public libraries in the Northeast held more titles, on average, from each of the checklists than public libraries in the other regions. Is this because public librarians in the Northeast are more attuned to the need for representations of diverse families and experiences? Or is it because many large cities are in the Northeast and large cities have large public library systems with extensive collections?

Finding that over 700 libraries held no titles from the LGBTQ checklist should prompt librarians to reconsider their selection practices and their youth collections. Of the 5,002 academic, public, and school libraries identified as actively collecting youth literature, only three held no titles from the race/ethnicity checklist. The authors were mildly concerned to realize that 48 libraries held none of the disability titles, but finding that $15 \%$ of libraries held no titles from the LGBTQ checklist was disturbing. Sexual orientation is 
a highly controversial topic in the United States, so it would be easy for selectors to unconsciously shy away from titles that are likely to be challenged. Librarians responsible for youth collections should make assessing their collections for LGBTQ-friendly titles a priority to verify that they are not unconsciously practicing censorship by selection. The results of this study should also remind librarians that while the Freedom to Read Statement was first adopted in 1953, its goals have not yet been met in all libraries. In a nation with increasing diversity, libraries need a renewed focus on serving all parts of our communities.

Looking at the Conspectus levels in Table 7 should encourage public librarians to assess their youth collections for representations of diversity. Most librarians would probably have predicted the findings, shown in Tables 5 and 6, that increased collection size and that increased collection expenditures were positively correlated with representations of diversity in public library youth collections. Table 7, however, shows that more than one-third of libraries spending over $\$ 100,000$ per year on materials did not achieve the minimal level for representations of racial/ethnic diversity or representations of disability, while half did not meet the minimal level for representations of LGBTQ orientation in youth collections. As noted above, it is possible that inconsistent setting of holdings in OCLC or strict weeding practices resulted in low Conspectus rankings for some public libraries, but these results also suggest that public libraries need to review their youth collections for representations of diversity.

\section{Conclusion}

This study used checklists to assess representations of diversity in youth collections based on OCLC holdings. The authors noted several potential problems, such as inconsistent setting of OCLC holdings, the possibility that older checklist titles may have been weeded before data collection commenced, difficulty of matching OCLC symbols with libraries in the Public Library Data Survey, and the need for caution in interpreting results given that some OCLC holding systems represented discrete libraries while others represented school districts, multi-branch public libraries, or regional library systems. Despite these limitations, the results indicate that librarians need to assess their youth collections for representations of diversity, particularly in representations of LGBTQ individuals. 
The results also suggest several areas for further research. For example, the authors developed a broad checklist for racial/ethnic diversity, but using a checklist of award-winning or highly recommended titles focused on a specific group might indicate that most libraries do collect the best of the best. The authors did not divide the checklists by the age range of materials; would using separate checklists for children and young adults reveal differences in collecting patterns, particularly of LGBTQ titles? The authors limited this study to OCLC holdings, which do not indicate whether a library holds one copy or many; assessing how well a multi-branch library system serves its population would require looking at both number of titles and number of copies.

This study was an attempt to assess the extent to which library youth collections reflect diverse families and life experiences. While the authors did not fully achieve their goals, the results suggest that children and teenagers from racial and ethnic minorities, youth with disabilities, and youth from families with LGBTQ members are finding few representations of people like themselves in many libraries.

Professional ethics require that libraries provide diverse youth collections, but doing so is also in libraries’ best interests. Minority populations are growing at a faster rate than the non-Hispanic White majority, the percentage of the population living with disabilities is likely to increase as health care improves and the population diversifies, and more people are publicly identifying as LGBTQ. According to File (2013), for the first time since the Census Bureau began tracking voting data by race, the percentage of eligible Black voters who voted in 2012 was higher than the percentage of eligible White voters (File, 2013). If libraries are to survive and thrive in the United States, libraries must work to appeal to members of minority populations and multiple constituencies. Providing youth collections that reflect diverse families and life experiences is one way that libraries can ensure that members of populations which have been discriminated against or disadvantaged feel welcomed and included in libraries today and in the future.

\section{REFERENCES}

Agosto, D. E., Hughes-Hassell, S., \& Gilmore-Clough, C. (2003). The all-White world of middle-school genre fiction: Surveying the field for multicultural protagonists. Children's Literature in Education, 34, 257-275. 
Allen County Public Library. (2005). Locations [Web page]. Retrieved from http://www.acpl.lib.in.us/ American Indian Library Association. (ca. 2006). American Indian Youth Literature Award. Retrieved from http://ailanet.org/activities/american-indian-youth-literature-award/.

American Library Association. (2013). Diversity in collection development. In ALA Policy Manual (section B.2.1.11). Retrieved from http://www.ala.org/aboutala/governance/policymanual/

American Library Association. (1996-2013a). Rainbow Project Committee. Retrieved from www.ala.org/glbtrt/about/committees/jnt-rainbowprj

American Library Association. (1996-2013b) Schneider Family Book Award. Retrieved from http://www.ala.org

American Library Association \& Association of American Publishers. (1953-2004). The Freedom to Read Statement. Retrieved from http://www.ala.org/advocacy/intfreedom/statementspols/freedomreadstatement

Andrews, S. E. (1998). Using inclusion literature to promote positive attitudes toward disabilities. Journal of Adolescent \& Adult Literacy, 41, 420-426.

Anthony, W. A. (1972). Societal rehabilitation: Changing society’s attitudes toward the physically and mentally disabled. Rehabilitation Psychology, 19, 117-126.

Asian Pacific American Library Association. (2011, June 1). Literature Award Guidelines. Retrieved from www.apalaweb.org/awards/literature-awards/literature-award-guidelines

Association for Library Service to Children, A Division of the American Library Association. (1996-2013). About the Pura Belpré Award. Retrieved from

http://www.ala.org/alsc/awardsgrants/bookmedia/belpremedal/belpreabout

Aud, S., Hussar, W., Kena, G., Bianco, K., Frohlich, L., Kemp, J., Tahan, K. (2011). The Condition of

Education 2011. (NCES 2011-033). United States Department of Education, National Center for Education Statistics. Washington, DC: U.S. Government Printing Office.

Bryant, E. (1995, June 15). Pride \& prejudice: LJ's survey of gay and lesbian library service. Library Journal, 120, 37-39.

Bushing, M., Davis, B., \& Powell, N. (1997). Using the Conspectus method: A collection assessment handbook. Lacey, Washington: WLN.

City of Rochester. (n.d.) Rochester Public Library Director's Message [Web page]. Retrieved from http://www.cityofrochester.gov/

Caldwell, N., Kaye, G., \& Mitten, L. A. (2007). "I” is for inclusion: The portrayal of Native Americans in books for young people. Retrieved from http://ailanet.org/about/publications/

Cooperative Children's Book Center, School of Education, University of Wisconsin-Madison. (n.d.). Children's books by and about people of color published in the United States. Retrieved from www.education.wisc.edu/ccbc/books/pcstats.asp 
Crosetto, A., Garcha, R., \& Horan, M. (2009). Disabilities and disorders in literature for youth: A selective annotated bibliography for K-12. Lanham: Scarecrow Press.

Cullinan, B. (1989). Literature and the child (2nd ed.). San Diego: Harcourt Brace Jovanovich.

Dodd, D. (1993). Historical statistics of the states of the United States: Two centuries of the census, 1790-1990. Westport, Connecticut: Greenwood Press.

Ethnic and Multicultural Information Exchange Round Table, American Library Association.

(1996-2013).The Coretta Scott King Book Awards. Retrieved from www.ala.org/emiert/cskbookawards

File, T. (2013). The diversifying electorate -- voting rates by race and Hispanic origin in 2012 (and other recent elections).Current Population Survey Reports, P20-569. Retrieved from United States Census Bureau website: http://www.census.gov/

Gates, G. J. (2011). How many people are lesbian, gay, bisexual, and transgender? The Williams Institute on Sexual Orientation and Gender Identity Law and Public Policy, School of Law, University of California Los Angeles. Retrieved from www.law.ucla.edu/williamsinstitute/

Gates, P. S., \& Mark, D. L. H. (2006). Cultural journeys: Multicultural literature for children and young adults. Lanham: Scarecrow Press.

Hughes-Hassell, S., \& Cox, E. J. (2010). Inside board books: Representations of people of color. Library Quarterly, 80, 211-230. doi: 10.1086/652873

Humes, K. R., Jones, N. A., \& Ramirez, R. R. (2011). Overview of race and Hispanic origin: 2010. 2010 Census Briefs, C2010BR-02. Retrieved from United States Census Bureau website: http://www.census.gov/

Jaeger, P. T., Subramaniam, M. M., Jones, C. B., \& Bertot, J. C. (2011). Diversity and LIS education: Inclusion and the age of information. Journal of Education for Library and Information Science, 52, 166-183.

Kurz, R. F. (2012). Missing faces, beautiful places: The lack of diversity in South Carolina Picture Book Award nominees. New Review of Children's Literature and Librarianship, 18, 128-145. doi:

10.1080/13614541.2012.716695

Larrick, N. (1965, September 11). The all-White world of children's literature. The Saturday Review, 48, 63-65, 84-85.

Lesniaski, D. (2004). Evaluating collections: A discussion and extension of brief tests of collection strength. College \& Undergraduate Libraries, 11, 11-24. doi: 10.1300/J106v11n01_02

Lofquist, D., Lugaila, T., O’Connell, M., \& Feliz, S. (2012). Households and families: 2010. 2010 Census Briefs, C2010BR-14. Retrieved from United States Census Bureau website: http://www.census.gov/

Manjarrez, C., Miller, K., Craig, T., Dorinski, S., Freeman M., Isaac, N., O’Shea, P., Schilling, P., Scotto, J. (2011). Data file documentation: Public libraries survey: Fiscal year 2009 (IMLS-2011-PLS-01). Institute of Museum and Library Services. Washington, DC. www.imls.gov/statistics 
Naidoo, J. C. (2012). Rainbow family collections: Selecting and using children's books with lesbian, gay, bisexual, transgender, and queer content. Santa Barbara, CA: Libraries Unlimited.

Nassau Library System. (2007-2012). NLS Online: About NLS. [Web page]. Retrieved from http://www.nassaulibrary.org/

OCLC. (2013). Find an OCLC library. [Data file]. Retrieved from http://www.oclc.org/contacts/libraries/

Pasco County Schools. (2013). 2012-2013 District School Board of Pasco County fact sheet. Retrieved from http://www.pasco.k12.fl.us/

Porta, M. A., \& Lancaster, F. W. (1988). Evaluation of a scholarly collection in a specific subject area by bibliographic checking: A comparison of sources. Libri, 30, 131-37. doi: 10.1515/libr.1988.38.2.131

Prater, M. A., Dyches, T. T., \& Johnstun, M. (2006). Teaching students about learning disabilities through children's literature. Intervention in School and Clinic, 42, 14-24. doi: 10.1177/10534512060420010301

Rogers, K. \& Writt, H. (2010). No rose-colored glasses needed: Learning about illnesses and disabilities through children's literature. Kentucky Libraries, 74 (1), 14-19.

Rainbow Books (2009, February 1). 2008 Rainbow List [Web log message]. Retrieved from http://glbtrt.ala.org/rainbowbooks/archives/153

Rothbauer, P. M. \& McKechnie, L. E. F. (1999). Gay and lesbian fiction for young adults: A survey of holdings in Canadian public libraries. Collection Building, 18, 32-39. doi: 10.1108/01604959910256526

Schneider, K. (2004, June 29). Remarks for Donor Katherine Schneider, Ph.D., L.P., ABPP, on the occasion of the first presentation of the Schneider Family Book Award. In Schneider Family Book Award Manual. Retrieved from www.ala.org/awardsgrants/awards/1/all_years

Sims, R. (1983). What has happened to the all-White world of children's books? Phi Delta Kappan, 64, 650-653.

Slapin, B. \& Seale, D. (Eds.) (1992). Through Indian eyes: The native experience in books for children. Philadelphia: New Society Publishers.

Slapin, B. \& Seale, D. (Eds.) (2005). A broken flute: The native experience in books for children. Walnut Creek, CA: AltaMira Press.

Smith, C. L. (2009, November 19). Editor interview: Lyn Miller-Lachmann on Multicultural Review. [Web log message]. Retrieved from

http://cynthialeitichsmith.blogspot.com/2009/11/editor-interview-lyn-miller-lachmann-on.html

Smith-D’Arezzo, W. M. (2003). Diversity in children’s literature: Not just a black and white issue.

Children's Literature in Education, 34, 75-94.

Smolen, L. A., \& Oswald, R. A. (Eds.) (2011). Multicultural literature and response: Affirming diverse voices. Santa Barbara: Libraries Unlimited.

South Central Library System. (2013). SCLS Directory of Public Libraries [Web page]. Retrieved from http://www.scls.info/ 
Spence, A. (1999). Gay young adult fiction in the public library: A comparative survey of public libraries in the US and Canada. Public Libraries, 38, 224-243.

Spence, A. (1998). Gay books in the public library: responsibility fulfilled or access denied? How nineteen large urban American and Canadian library systems compare in service to their communities. Toronto: International Information Research Group.

Stringer-Stanback, K. (2011). Young adult lesbian, gay, bisexual, transgender, and questioning (LGBTQ) non-fiction collections and countywide anti-discrimination policies. Urban Library Journal, 17. Retrieved from http://ojs.gc.cuny.edu/index.php/urbanlibrary.

Sweetland, J. H. \& Christensen, P. G. (1995). Gay, lesbian and bisexual titles: Their treatment in the review media and their selection by libraries. Collection Building, 14 (2), 32-41. doi: 10.1108/eb023399

Twiss, T. M. (2001). A validation of brief tests of collection strength. Collection Management, 25, 23-32. doi: 10.1300/J105v25n03_03

United States Census Bureau. (n.d.). Census regions and divisions of the United States. Retrieved from http://www.census.gov/geo/www/us_regdiv.pdf

United States Census Dataset 2010 Summary File 1. (2010). [Data file]. Retrieved from http://www.census.gov/

Walling, L. L. (2010). Evaluating materials about children with disabilities [Web page]. Retrieved from http://faculty.libsci.sc.edu/walling/evaluatingmaterialsabout.htm.

White, H. D. (1995). Brief tests of collection strength: A methodology for all types of libraries. Westport, Connecticut: Greenwood Press.

Yokota, J. (1993). Issues in selecting multicultural children’s literature. Language Arts, 70, 156-167. 